\title{
ADESÃO DA EQUIPE DE ENFERMAGEM NA HIGIENE DAS MÃOS
}

\author{
Ana Maria Jorge ${ }^{1}$, Chennyfer Dobbins Abi Rached ${ }^{3}$ \\ 1 Graduanda de Enfermagem. Universidade Nove de Julho - UNINOVE. São Paulo - Brasil - Email: \\ São Paulo - Brasil \\ 3 Doutora em Saúde Coletiva; Mestre em Economia da Saúde pela Universidade Federal de São Paulo \\ (UNIFESP); Docente do Programa de Mestrado Profissional em Gestão em Sistemas de Saúde - \\ Universidade Nove de Julho - UNINOVE. São Paulo - Brasil email: chennyferr@yahoo.com.br \\ ORCID: https://orcid.org/0000-0002-4499-3716
}

\section{RESUMO}

Atualmente, um dos maiores problemas relacionados a segurança do paciente em todo o mundo é a infecção cruzada. O principal meio de transmissão de patógenos responsáveis por infecções nosocomiais são as mãos. A higienização das mãos é uma das medidas preventivas mais eficazes para prevenir as infecções, mas apenas $50 \%$ dos profissionais da área da saúde adotam essa medida. O objetivo deste trabalho é descrever os benefícios que a prática da higienização das mãos proporciona para o cliente, profissional de enfermagem e instituição. A pesquisa foi realizada por revisão bibliográfica desenvolvida através de publicações cientificas preferencialmente, no período de 2012 a 2018, utilizando para levantamento dos dados as bases de dados Literatura Latino-Americana e do Caribe em Ciências da Saúde (LILACS), BDENF do portal da Biblioteca Virtual em Saúde (BVS-BIREME) e base de dados Scientific Electronic Library Online (SCIELO). Esta análise de revisão literária ampliou conceitos sobre a importância da prática da higienização das mãos pelos profissionais da área da saúde.

Palavras chave: Enfermagem higienização das mãos, lavagem das mãos, contaminação cruzada hospitalar, prevenção de doenças nosocomiais.

\section{ABSTRACT}

Currently, one of the biggest problems related to patient safety around the world is cross infection. The main means of transmission of pathogens responsible for nosocomial infections are the hands. Hand hygiene is one of the most effective preventative measures to prevent infections, but only $50 \%$ of health professionals take this action. The objective of this work is to describe the benefits that the practice of hand hygiene provides for the client, nursing professional and institution. The research was carried out by a bibliographical review developed through scientific publications preferably in the period from 2012 to 2018, using the Latin American and Caribbean Literature in Health Sciences databases (LILACS), BDENF from the Library portal Virtual Health Library (VHL-BIREME) and Scientific Electronic Library Online (SCIELO) database. This review of literary review extended concepts about the importance of the practice of hand hygiene by health professionals. 
Key words: Nursing hand hygiene, hand washing, hospital cross-contamination, nosocomial disease prevention.

\section{INTRODUÇÃO}

Atualmente, um dos maiores problemas relacionados a segurança do paciente em todo o mundo é a infecção cruzada. O principal meio de transmissão de patógenos responsáveis por infecções nosocomiais são as mãos ${ }^{1}$.

As mãos são colonizadas por microrganismos. Na camada superior da pele existe microrganismos transitórios que facilmente são removidos com a higienização. Na camada mais profunda da pele temos os microrganismos residentes, estes não são facilmente removidos e não estão associados a contaminação cruzada. Devido a inúmeros procedimentos, as mãos de alguns profissionais podem estar colonizadas na camada mais profunda da pele por patógenos como o S. aureus e bacilos Gramnegativos, podendo alcançar até “4,6x106 UFC/cm3” de contaminação, assim, esses profissionais, caso não realizem a higienização adequada estão colaborando com a infecção nosocomial mesmo quando esses patógenos se encontram na camada profunda da pele ${ }^{2}$.

Devido à falta de tempo, grande demanda de atendimentos e procedimentos ou até mesmo esquecimento muitos profissionais da área da saúde, incluindo a equipe de enfermagem não realizam regularmente a higienização das mãos adequadamente ${ }^{1}$. Este procedimento é uma das medidas preventivas mais eficazes para o controle de infecções, segundo estudos, nem todos os profissionais higienizam as mãos frequentemente ou de modo adequado no Brasil e demais países, de um modo geral apenas $50 \%$ dos profissionais da área da saúde adotam essa medida e enfermeiros que recebem treinamento contínuo os índices chegam a $80 \%{ }^{3,4}$. 
Conforme recomendações da Organização Mundial da Saúde (OMS), existem cinco momentos essenciais que a higienização das mãos deve ser realizada, sendo: antes de entrar em contato com o cliente e procedimentos assépticos, depois de se expor a secreções corporais, contato com o cliente e pertences do mesmo ${ }^{1}$.

O paciente exposto a infecções nosocomiais torna-se mais vulnerável ao aumento de tempo de hospitalização, resistência a antibioticoterapia e os gastos elevam-se ${ }^{5}$.

Desde o ano de 2004, a OMS e a ANVISA criaram metas internacionais visando a segurança do paciente e, entre os anos de 2005 e 2006 foi lançado um desafio mundial, chamado de "uma assistência limpa é uma assistência mais segura". Esse desafio tinha como objetivo reduzir a incidência de infecção nosocomial, dentre as estratégias, estava a prática de higienização das mãos ${ }^{5}$.

E, desde o ano de 2008 a OMS estimula a implantação de melhorias como melhor estrutura física, uso de sabonete, solução alcoólica, toalhas descartáveis, treinamento e educação continuada das equipes multiprofissionais e lembretes na instituição para clientes, acompanhantes, visitantes e colaboradores em todos os setores das instituições de saúde para que a prática da higienização das mãos seja realizada com eficácia ${ }^{5}$.

O profissional que não adere a prática de higienização adequada pode responder judicialmente e ser processado por negligência, caso haja comprovação de danos decorrentes da falta de higienização (contaminação cruzada) ${ }^{1}$.

\subsection{Problema de pesquisa}

Qual a importância da higienização das mãos entre os profissionais da enfermagem para evitar a transmissão de microrganismos? 


\subsection{Justificativa}

Considerando a realidade brasileira e mundial de que a prática da higienização das mãos é um procedimento fundamental antes e após a realização de atividades voltadas para a área da enfermagem e demais áreas clínicas se faz necessário buscar evidências científicas através de revisão literária para identificas quais são os benefícios para o cliente, colaboradores e instituição que aderem à prática citada.

\section{OBJETIVOS}

\subsection{Objetivos gerais}

Buscar evidências científicas para identificar quais são os benefícios da prática de higienização das mãos nos serviços de saúde.

Buscar evidências científicas para identificar quais são os principais danos ao paciente e ao profissional da área da saúde decorrentes da falta de higienização das mãos.

\subsection{Objetivo específico}

O presente trabalho tem como objetivo realizar revisão literária para descrever os benefícios que a prática da higienização das mãos proporciona para o cliente, profissional de enfermagem e instituição.

\section{METODOLOGIA}

\subsection{Tipo de Estudo}

Trata-se de uma revisão de literatura, que consiste em um levantamento de referências teóricas já analisadas anteriormente, por procedimento reflexivo, sistemático, controlado e crítico, permitindo a descoberta de novos fatos ou dados, 
relações ou leis, em qualquer campo de conhecimento. Esta pode ser caracterizada como o primeiro passo do pesquisador para realizar uma pesquisa cientifica; através dela é possível fazer levantamentos dos dados já existentes em material publicado, constituído principalmente por livros-texto, artigos científicos, dissertações, entre outros $^{6}$

\subsection{Contexto}

A busca de pesquisas para elaboração da revisão integrativa foi realizada em banco de dados de acesso livre, trabalhos publicados em português nas bases de dados Literatura Latino-Americana e do Caribe em Ciências da Saúde (LILACS) e BDENF do portal da Biblioteca Virtual em Saúde (BVS-BIREME) e base de dados Scientific Electronic Library Online (SCIELO).

Foram utilizados como critério de inclusão os artigos de pesquisas indexados nas bases de dados entre os anos de 2012 até 2018, no idioma em português que estavam disponibilizados sua versão na íntegra, para a realização da pesquisa os descritores foram utilizados em português.

\subsection{Coleta dos Dados}

A coleta de dados foi realizada pela pesquisadora. Para tanto, foi utilizado um instrumento de coleta de dados que abordará os passos necessários a resposta da questão da revisão integrativa, como: nome do autor; título da obra; base de indexação, procedência da publicação; local e ano, objetivos; principais resultados e conclusões.

A questão norteadora desta pesquisa foi: Qual a importância da higienização das mãos entre os profissionais da enfermagem para evitar a transmissão de microrganismos? 
A coleta do material foi feita por meio dos Descritores de Ciências da Saúde (DeCS) uma busca nas bases de dados bibliográficas selecionadas de documentos de pesquisas primárias referente ao tema adesão da equipe de enfermagem na higiene das mãos.

Nesta etapa da coleta foram utilizados os descritores: Enfermagem higienização das mãos, lavagem das mãos, contaminação cruzada hospitalar, prevenção de doenças nosocomiais, consultados por palavra ou termo e por índice permutado. Desta pesquisa foram obtidos os resultados do quadro 1.

\begin{tabular}{|l|c|c|l|l|}
\hline $\begin{array}{l}\text { DeCS/ Bases } \\
\text { de Dados }\end{array}$ & $\begin{array}{l}\text { Enfermagem } \\
\text { higienização das } \\
\text { mãos AND }\end{array}$ & $\begin{array}{l}\text { Lavagem das } \\
\text { mãos AND }\end{array}$ & $\begin{array}{l}\text { contaminação } \\
\text { cruzada } \\
\text { hospitalar AND }\end{array}$ & $\begin{array}{l}\text { prevenção } \\
\text { doenças } \\
\text { nosocomiais }\end{array}$ \\
\hline LILACS & 82 & 256 & 19 & 209 \\
\hline SCIELO & 36 & 50 & 0 & 2 \\
\hline BDENF & 5 & 4 & 0 & 1 \\
\hline
\end{tabular}

Os artigos foram analisados, comparados e observados quanto sua semelhança e/ou divergência para a realização do desenvolvimento do tema.

\section{DESENVOLVIMENTO}

\section{Tipos de higienização das mãos, produtos e finalidades}

A higienização das mãos tem como finalidade a prevenção e controle de infecções relacionadas a assistência prestada nos serviços de saúde, visando a segurança dos clientes e colaboradores ${ }^{7}$.

O protocolo de higiene das mãos deve ser inserido em todos os tipos de serviços e unidades hospitalares, sejam em instituições públicas, privadas ou filantrópicas, independentemente do nível de complexidade ou localização ${ }^{7,8}$. 
Os produtos devem estar em local de fácil acesso e visualização, se possível, no local onde será realizado o atendimento, fixados em paredes ou em leito e fazer parte dos produtos encontrados em carrinhos de curativos ${ }^{7}$.

De acordo com a Agência Nacional de Vigilância Sanitária (ANVISA) existem 2 tipos de higienização das mãos: higiene simples: Procedimento que utiliza água e sabonete líquido e higiene antisséptica: Procedimento que utiliza água e sabonete, seguido do uso de produto antisséptico e/ou degermante ${ }^{7}$.

Os antissépticos utilizados são:

Solução alcoólica: reduz a quantidade de microrganismos nas mãos. Quando utilizado por meio de fricção não há necessidade de se realizar o enxágue, deve-se secar com papel toalha ou equipamento apropriado ${ }^{7,9}$.

Preparação alcoólica líquida com concentração de álcool entre 60 à $80 \%$ : reduz a quantidade de microrganismos encontrados nas mãos e evita o ressecamento da pele caso haja emolientes ${ }^{7,9}$.

Preparação alcoólica em gel (álcool gel) e espumas: a concentração mínima de álcool nesses produtos deve ser, no mínimo em $70 \%^{7,9}$.

Os cinco momentos de higiene das mãos são padronizados e devem ser realizados antes e após o contato com o cliente, manusear dispositivos invasivos, ao movimentar sítios contaminados, após a exposição de fluidos ou secreções corpóreas e tocar objetos hospitalares ou pertences do cliente, antes e após o uso de luvas ${ }^{7}$.

A higienização realizada com água e sabonete líquido deve ser feita quando as mãos estiverem visivelmente sujas ou quando entrar em contato direto com fluídos corporais, após utilizar o sanitário. Promove limpeza nas camadas superficiais da pele como por exemplo, células mortas, oleosidade, sujidades e suor. Evita a proliferação 
de microrganismos. O tempo da realização do procedimento deve ser de 40 a 60 segundos ${ }^{7}$.

Higienização com preparação alcoólica: deve ser realizada antes e após entrar em contato com o cliente, antes e após a utilização de luvas de procedimento, antes de manusear fármacos e alimentos ${ }^{7}$.

A higienização com água e degermante associada ao uso de solução antisséptica remove a microbiota transitória, sujidades e reduz a microbiota residente da pele. $\mathrm{O}$ tempo da realização do procedimento deve ser de 40 a 60 segundos ${ }^{7}$.

A higienização por meio de fricção com preparação alcoólica reduz a microbiota presente nas mãos e, quando as mãos não estiverem visivelmente sujas pode substituir a higienização simples em alguns casos. O tempo da realização do procedimento deve ser de 20 a 30 segundos $^{7}$.

\section{Estratégias para ampliar a prática da higienização das mãos}

As medidas estratégicas para a adoção da prática rotineira da higienização das mãos englobam um conjunto de ações nas quais utilizam ferramentas estratégicas para modificar as práticas dos profissionais da área da saúde ${ }^{10}$.

Dentre as estratégias, é necessário disponibilizar os produtos em locais de fácil acesso, visibilidade e fácil manejo, implantar torneiras de acionamento automático ${ }^{10}$. Capacitar e oferecer treinamento continuado aos profissionais. Anexar lembretes em locais estratégicos sobre a higienização e modo correto de se realizar o procedimento, monitorar e avaliar os colaboradores da instituição. Enfatizar a importância da segurança do paciente e o que essa prática representa ${ }^{10}$.

\section{Benefícios higienização das mãos}

A portaria do Ministério da Saúde (MS) número 2616 do ano de 1998 torna obrigatória a implantação de programas de controle de infecção hospitalar nas instituições de 
saúde e a RDC 50 de 2002 estabelece normas e ações a serem realizadas em ambiente hospitalar para a redução de contaminação e infecções relacionadas a prestação de serviços. Dentre essas ações, uma das prioritárias é a prática da higiene das mãos ${ }^{11}$.

A prática da higienização é uma medida de prevenção primária à baixo custo. É uma grande aliada no controle de infecção hospitalar, reduz os índices de mortalidade, tempo de permanência hospitalar do cliente e promove qualidade de atendimento, além de prevenir doenças como a pneumonia nosocomial, infecção do trato urinário, infecção de sítio cirúrgico, sepse, entre outras ${ }^{11,12}$.

\section{CONSIDERAÇÕES FINAIS}

Esta análise de revisão literária ampliou conceitos sobre a importância da prática da higienização das mãos pelos profissionais da área da saúde.

Essa prática é simples e apresenta baixo custo, proporciona segurança ao paciente, evitando danos decorrentes a assistência prestada como infecções e pneumonia nosocomial, otimizando os serviços prestados e reduzindo o tempo de internação e custos institucionais decorrentes a contaminação por meio das mãos.

Os profissionais envolvidos nos cuidados devem se conscientizar sobre a importância da prática e implantá-la em seu cotidiano para garantir segurança ao paciente, contribuindo, assim para a qualidade da assistência prestada.

Há poucas publicações recentes acerca do assunto, porém, as citadas neste estudo supriram a necessidade do que foi proposto investigar.

\section{REFERÊNCIAS BIBLIOGRÁGICAS}

1. Trannin KPP, Campanharo CRV, Lopes MCBT, Okuno MFP, Batista REA. Adesão à higiene das mãos: intervenção e avaliação. Cogitare Enf. 2016; 21(2): 01-07. Disponível: https://revistas.ufpr.br/cogitare/article/view/44246/28015 [acessado 10 de maio de 2018]. 
2. Custódio J, Alves JF, Silva FM, Dolinger EJOV, Santos JGS, Brito DVD. Avaliação microbiológica das mãos de profissionais da saúde de um hospital particular de Itumbiara, Goiás. Rev. Ciên. Méd. 2012; 8(1):7-11. Disponível: http://periodicos.puccampinas.edu.br/seer/index.php/cienciasmedicas/article/view/6 49/629 [acessado 10 de maio de 2018].

3. Oliveira AC, Paula AO. Intervenções para elevar a adesão dos profissionais de saúde à higiene de mãos: revisão integrativa. Rev. Eletr. Enf. 2015;15(4):1052-1060. Disponível: http://dx.doi.org/10.5216/ree.v15i4.21323 [acessado 10 de maio de 2018].

4. Giordani AT, Sonobe HM, Ezaias GM, Valério MA, Andrade D. Adesão da equipe de enfermagem à higienização das mãos: fatores motivacionais. Rev Rene. 2014; 15(4):559-568. Disponível: http://www.redalyc.org/html/3240/324032212 002/ [acessado 10 de maio de 2018].

5. Santos TCR, Roseira CE, Piai-Morais TH, Figueiredo RM. Higienização das mãos em ambiente hospitalar: uso de indicadores de conformidade. Rev. Gaúcha Enf. 2014;35(1):70-77. Disponível: http://www.seer.ufrgs.br/index.php/ RevistaGaucha deEnfermagem/article/view/40930/28935 [acessado 10 de maio de 2018].

6. Gerhardt TE, Silveira DT [organizadores]. Métodos de Pesquisa. P. 37, 90. Porto Alegre: Editora UFRGS, 2009. Disponível: http://zip.net/bpnzXX. [acessado 30 de maio de 2018].

7. BRASIL. Ministério da Saúde. Anvisa. Fiocruz. Protocolo para a prática de higiene das mãos em serviços de saúde. 2013. Anexo 01. Disponível: https://www20.anvisa .gov.br/segurancadopaciente/index.php/publicacoes/category/diversos [acessado 13 de setembro de 2018].

8. Mota EC, Barbosa DA, Silveira BBRM, Rabelo TA, Silva NM, Ribeiro JL et al. Higienização das mãos: uma avaliação da adesão e da prática dos profissionais de saúde no controle das infecções hospitalares. Rev Epidemio Control Infect. 2014;4(1):12-17. Disponível: https://online.unisc.br/seer/index.php/epidemiologia/arti cle/view/4052 [acessado 13 de setembro de 2018]. 
9. Belela-Anacleto ASC, Peterlini MAS, Pedreira MLG. Higienização das mãos como prática do cuidar: reflexão acerca da responsabilidade profissional. Rev Bras Enf. 2017;70(2):461-464. Disponível: http://www.scielo.br/pdf/reben/v70n2/pt_0034-7167reben-70-02-0442.pdf [acessado 16 de setembro de 2018].

10. Rodríguez EOL, Oliveira JKA, Menezes MO, Silva LSL, Almeida DM, Lopes Neto D. Aderência de profissionais de saúde à higienização das mãos. Rev Enf UFPE. 2018; 12(6):1578-1585. Disponível: https://periodicos.ufpe.br/revistas/revistaenferma gem/article/viewFile/230841/29186 [acessado 16 de setembro de 2018].

11. Souza LM, Ramos MF, Beckerc ESS, Meirelles LCS, Monteiro SAO. Adesão dos profissionais de terapia intensiva aos cinco momentos da higienização das mãos. Rev. Gaúcha Enf. 2015;36(4): 21-28. Disponível: http://www.scielo.br/scielo.php?Script =sci_arttext\&pid=S1983-14472015000400021\&lng=en\&nrm=iso [acessado 16 de setembro de 2018].

12. Araujo AP, Nóbrega GB, Santos LFC, Aragão RS, Pontes AAN. Análise da higienização das mãos pelos profissionais de saúde em ambiente hospitalar durante dois meses. Rev S. Ciên. 2015; 4(3): 44-54. Disponível: http://www.ufcg.edu.br /revistasaudeeciencia/index.php/RSC-UFCG/article/viewFile/297/202 [acessado 16 de setembro de 2018]. 